\title{
Über den Einfluß des Rohrposttransportes auf klinisches Untersuchungsmaterial unter verschiedenen Betriebsbedingungen
}

\author{
Von A. Delbrück und H. Poschmann
}

\begin{abstract}
Aus dem Zentrallaboratorium der Med. Klinik der Med. Hochschule Hannover (Direktor: Prof. Dr. F. Hartmann) und der Robrpostabteilung der Standard Elektrik Lorenz AG, Berlin-Scböneberg
\end{abstract}

(Eingegangen am 27. September 1967)

\begin{abstract}
In ciner Rohrpostversuchsanlage wurde unter verschiedenen Betriebsbedingungen der Einfluß der während des Transportes auftretenden mechanischen und kinetischen Faktoren auf Untersuchungsgut für das klinische Laboratorium untersucht.

Das Ausmaß einer transportbedingten Hämolyse hängt im wesentlichen von der Füllungshöhe der Probenröhrchen ab. Kontrollierte Transportbedingungen erlauben einen störungsfreien Transport ohne Auftreten von nennenswerten Hämolysen. In Testreihen wurde für 33 klinisch-chemische bzw. hämatologisch-serologische Analysenverfahren keine Einschränkung der Zuverlässigkeit der Meßergebnisse gefunden. Für den Transport von Laboratoriumsmaterial empfiehlt sich eine $124 \mathrm{~mm}$ Rohrpostanlage, die mit $3 \mathrm{~m} / \mathrm{Sek}$. Fahrgeschwindig-
\end{abstract} keit ohne Weichen, Klappen, Zentrale usw. arbeitet.

With the aid of an experimental pneumatic installation, the mechanical and kinetic effects of transport by pneumatic post were studied on experimental clinical material. The extent of hemolysis caused by transport depends chiefly on the level to which the sample tube is filled. Under certain predetermined conditions, the transport has no effect and there is no significant hemolysis. In a series of 33 clinical chemical or hematological-serological analyses, there was no decrease in the dependability of the results. For the pneumatic transport of laboratory material, a $124 \mathrm{~mm}$. tube with no deflectors, flaps, central-deflectors etc. is recommended, which carries material at the rate of $3 \mathrm{~m} / \mathrm{sec}$.

Die schnelle Anlieferung qualitativ unveränderten Untẹrsuchungsmaterials ist von ausschlaggebender Bedeutung für die Arbeit im klinisch-chemischen Laboratorium. Es erscheint daher vorteilhaft, anstelle des herkömmlichen Hol- und Bringedienstes eine der heute zur Verfügung stehenden mechanischen Transporteinrichtungen zu benutzen, deren Betriebsbedingungen einer exakten Kontrolle zugänglich sind. Unter diesen mechanischen Transportsystemen steht uns in der Rohrpost ein über Jahrzehnte hin bewährtes, zuverlässiges und schnellẹs Transportmittel zur Verfügung. Jedoch wurden gegẹn die Benutzung einer Rohrpost zum Transport von Laboratoriumsmaterial eine Reihe von Einwänden erhoben. Unter anderem wurde auf eine transportbedingte Verfälschung der Analysenergebnisse infolge Hämolyșe in Vollblutproben, Denaturierung biologischer Eiweiß̧körper oder auch auf Verunreinigung der Rohrpostanlage durch Behälterbruch hingewiesen. Erste Daten über den Einfluß des Rohrposttransportes auf Untersuchungsmaterial, insbesondere über das Auftreten einẹ Hämolyse wurden 1964 von McClellan und Mitarbeitern berichtet (1). Die Ergebnisse dieser Autoren veranlaßten uns, den Einfluß der verschiedenen Faktoren, welche während des Rohrposttransportes auf das Material einwirken, einer detaillierteren Untersuchung zu unterwerfen, um Rohrpostbetriebșbedingungen zu finden, welche einen störungsfreien Transport des Untersuchungsgutes von den Stationen zum Laboratorium ermöglichen. $\mathrm{Zu}$ diesem Zweck wurde eine Rohrpostversuchsanlage mit variierbaren Betriebsbedingungen eingerichtet, Untersuchungsgut unter verschiedenen Transportbedingungen versandt und anschließend einer breiten klinisch-chemischen und hämatologisch-serologischen Prüfung unterzogen.

\section{Methoden und Material}

Robrpostversuchsanlage (Standard Elektrik Lorenz AG, Berlin). $20 \mathrm{~m}$ vertikal, $20 \mathrm{~m}$ horizontal und $20 \mathrm{~m}$ in Krümmungen $(1,5 \mathrm{~m}$ Radius) als geschlossenes Rohrsystem verlegte Fahrrohrleitung mit einem inneren Durchmesser von $100 \mathrm{~mm}$. Weichen- und Ausfahreinheit mit $90^{\circ}$ horizontaler Ablenkung zur Imitation von Weichenpassagen. Saugluftbetrieb mit 1,1 m Wassersäule maximaler Druckdifferenz, durch $1,5 \mathrm{kw}$ 3-Phasenmotor angetriebenes Gebläse mit $5 \mathrm{~m}^{3} / \mathrm{Min}$. Luftumwälzungsvermögen. Variation der Fahrgeschwindigkeit von $1-8 \mathrm{~m} / \mathrm{Sek}$. durch eine verstellbare Drosselklappe. Durch das Kreissystem von $60 \mathrm{~m}$ Länge ergab sich eine unbegrenzte Variation der Fahrstreckenlänge (Abb. 1a).

Versandbüchsen aus Kunststoff, Verschluß durch Hartgummideckel mit Druckknopf. Bakeliteinsätze zur Aufnahme der Probegefäße

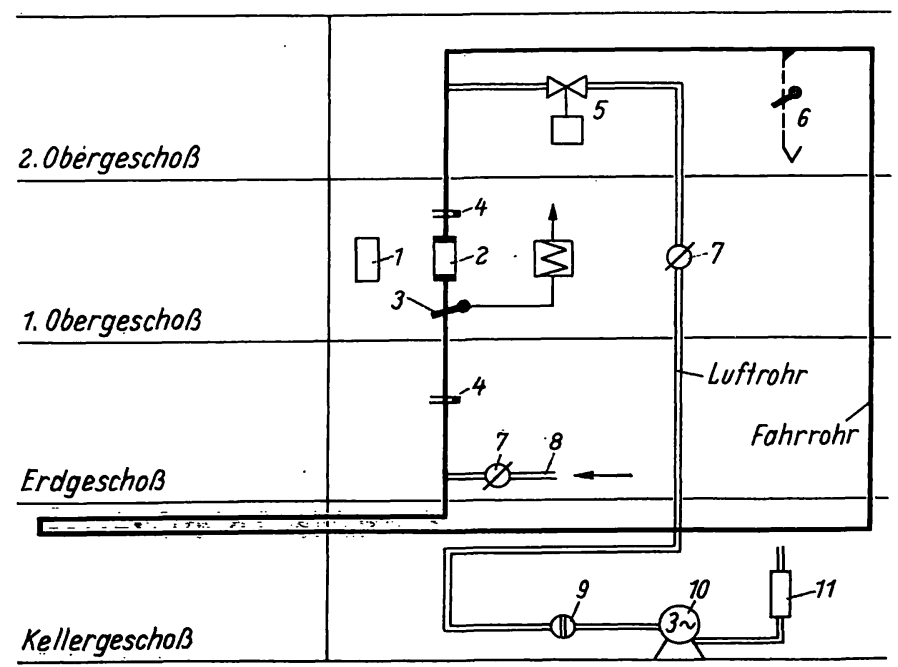

Abb. 1a

Schaltbild der Rohrpostversuchsanlage. Jeder Fahrrohrbogen hat einen Radius von $1,5 \mathrm{~m}$

1 Steuergerät; 2 Schiebesender; 3 elektromagnetisch gesteuerte Zwischenklappe; 4 Rohrkontakt; 5 Elektroventil; 6 WaagerechtEinstellen der Fahrgeschwindigkeit; 8 Luftansaugrohr; 9 Luftilter; 10 Gebläseanlage; 11 Schalldämpfer 


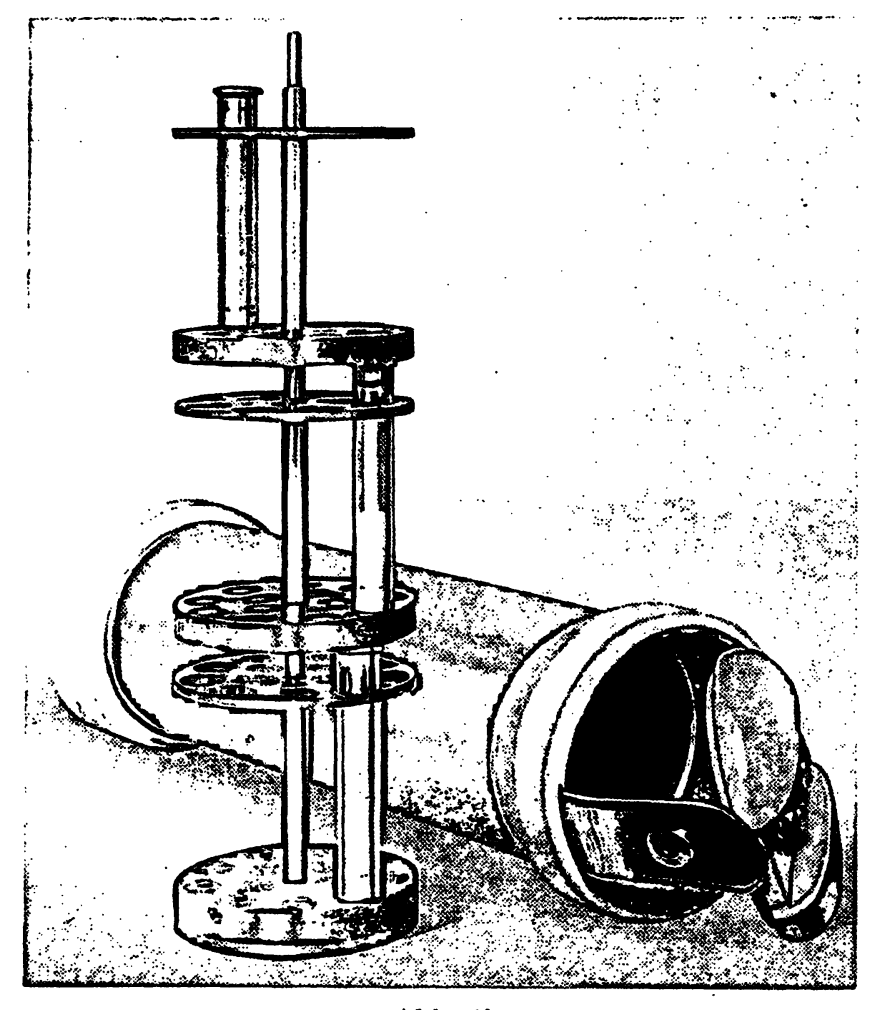

Abb. $1 b$

Rohrposttransportbüchse mit Einsatzstab zur Aufnahme von 3 Haltern für jeweils 13 Versandröhrchen $(15 \mathrm{ml})$ bzw. 3 Sputumgefäßen $(30 \mathrm{ml})$

auf zentraler Schiene übereinander angeordnet zur Erleichterung der Be- und Entladung (Abb. $1 \mathrm{~b}$ ).

Proberöhrchen, $15 \mathrm{~m}$ l fassend, aus Glas oder Kunststoff durch Kunststoffstopfen mit glatter innerer Oberfläche verschlossen, sowie Kunststoffbüchsen $30 \mathrm{~m} /$ Inhalt zur Aufnahme von Stuhl, Sputum und ähṇlichem Material.

\section{Durchfiubrung der Versucbsreiben}

Nativ- und Citratblutproben gesunder Blutspender und eine Reihe pathologisch veränderter Blutproben wurden uniter verschiedenen Betriebsbedingungen in der Rohrpost transportiert. Für jeden Versuch wurden Vergleichsproben angesetzt, die zur gleichen Zeit entnommen, zentrifugiert und analysiert wurden wie die Proben, welche dem Rohrposttransport unterworfen waren. Um mögliche Varianten in den mechanischen Faktoren während der einzelnen Rohrpostläufe zu erfassen, wurden Parallelproben in jeweils verschiedenen Testläufen in der Rohrpost transportiert.

Zur Erfassung der Hämolyse wurden im Serum bzw. Plasma Hämoglobin (Mikrobestimmung mit Benzidin (2,3)), Lactatdehydrogenase $^{1}$ ), Gluccse-6-phosphatdehydrogenase, Pyruvatkinase und Glutathionreduktase (4), sowie Kalium bestimmt.

1) Abkiirzungen und Enz'me:

LDH: Lactatdehydrogenase (EC 1.1.1.27 L-Lactat: NAD Oxydoreduktase).

G-6-PDH: Glucose-6-Phosphatdehydrogenase (EC 1.1.1.49 DGlucose-6-Phosphat: NADP Oxydoreduktase)

PK: Pyruvatkinase (EC 2.7.1.40 ATP: Pyruvattransferase)

GR: Glutathionreduktase (EC 1.6.4.2 $\mathrm{NAD}(\mathrm{P}) \mathrm{H}_{2}$ : Glutathion Oxydoreduktase)

GOT: Glutamatoxalacetattransaminase (ĖC 2.6.1.1. L-Aspartat: 2 Oxoglutarat Aminotransferase)

GPT: Glutamatpyruvattransaminase (EC 2.6.1.2. x-Alanin: 2 Oxoglutarat Aminotransferase)

GLDH: Glutamatdehydrogenase (EC 1.4.1.2. L-Glutamat: NAD Oxydoreduktase (desaminierend)

CPK: Creatinphosphokinase (EC 2.7.3.2. ATP; Creatin Phosphotrạnsferase)
Der Einfluß des Rohrposttransportes auf die Zuverlässigkeit klinisch-chemischer Analysen wurde an folgenden weiteren Testverfahren geprüft: Glutamatoxalacetattransaminase, $n=10$, Glutamatpyruvattransaminase, $n=9$, Glutamatdehydrogenase, $n=9$, Creatinphosphokinase, $n=8$, Saure Phosphatase, $\left.n=10(\mathrm{I})^{2}\right)$, Alkalische Phosphatase, $\mathrm{n}=10$ (5), $\alpha$-Amylase, $\mathrm{n}=10 \quad(6)$, Kalium, $\mathrm{n}=19$, Natrium, $\mathrm{n}=19$, Calcium, $\mathrm{n}=10$, (flammenphotometrische Bestimmung), Eisen, $n=18$ (II), Chlorid, $n=18$ (III), Anorganisches Phosphat, $\mathrm{n}=10$ (6), Bilirubin, $\mathrm{n}=10$ (7), Cholesterin, $n=10$ (IV), Kreatinin, $n=10$ (8), Harnstoff, $n=9$ (I), Harnsäure, $n=10$ (V), Eiwei $\beta, n=10$ (9), Elektrophorese der Serumeiweißkörper, $\mathrm{n}=10(10, \mathrm{VI})$.

Hämatologisch-serologisch wurden geprüft: Blutzellenzählung aus versandter Kochsalzverdünnung im Coulter Counter, $n=20$ (VII), Thrombocyten, $\mathrm{n}=8$, Prothrombinzeit, $\mathrm{n}=10$ (VIII), Thrombinzeit, $\mathrm{n}=10$ und Faktor V, $\mathrm{n}=10$ (IX). Antistreptolysintiter, $\mathrm{n}=10$ (11) und Rheumafaktor, $\mathrm{n}=10$ (12), Blutgruppen, $\mathrm{n}=10$.

Die Temperaturkontrolle wurde im Inneren des Transportbehälters durch Mitführen eines Maximumthermometers in einem wassergefüllten Transportgläschen über eine Fahrstrecke von $1,2 \mathrm{~km}$ bei maximaler Geschwindigkeit vorgenommen.

\section{Ergebnisse}

Während des Transportes wurde in den Rohrposttransportbehältern eine Maximaltemperatur von $22^{\circ}$ gemessen. Ein Bruch der Transportgefäße, Austritt von Untersuchungsgut an den Verschlußkappen und eine damit verbundene Verunreinigung der Transportbehälter oder des Rohrpostsystems wurde in keinem der Testläufe beobachtet.

Für die Untersuchungen über den Gràd der während des Transportes von Vollblut oder Citratblut auftretenden Hämolyse erwies sich die Hämoglobinkonzentration im Serum als der empfindlichste Parameter, während LDH, G-6-PDH und Kalium erst bei stark sichtbaren Hämolysen signifikant erhöht im Serum auftraten. Das Aus$\mathrm{maß}$ der Hämolyse war vorwiegend von dem Grad der Füllung der versandten Proberöhrchen abhängig (Abb. 2). Sowohl beim Transport von Nativblut wie von $\mathrm{Ci}-$ tratblut fand sich eine deutliche Zunahme der Hämoglobinkonzentration im Serum nur dann, wenn die Gefäße nicht vollständig gefüllt transportiert wurden. Eine nennenswerte Zunahme der Hämoglobinkonzentration im Serum bzw. im Plasma wurde nicht beobachtet, wenn die Röhrchen bis zum Verschlußstopfen gefüllt dem Transport unterworfen wurden. Dies gilt in gleichem Maße für eine Fahrgeschwindigkeit von $3 \mathrm{~m} / \mathrm{Sek}$. ohne Passieren von Weichen wie für eine Fahrgeschwindig-

s. P'ase: Saure Phosphatase (EC 3.1.3.2. Orthophosphorsäure Monoester Phosphohydrolase)

alk. P'ase: Alkalische Phosphatase (EC 3.1.3.1. Orthophosphorsäure Monoester Phosphohydrolase)

$\alpha$-Amylase: (EC 3.2.1.1. $\alpha$-1,4-Glucan-4-glucanohydrolase)

Arginase: (EC 3.5.3.1. L-Arginin Amidinohydrolase)

2) Bezugsquellen:

I. C. F. Boehringer \& Soehne GmbH, Mannheim

II. Schweizerhall Chem. Fabrik, Basel/Schweiz

III. E. Merck'AG, Darmstadt

IV. Hyland Laboratories, Los Angeles, Cal./USA

V. Sigma Chem. Corp. St. Louis, Miss./USA

VI. Technicon Corp., Chauncey, N. Y./USA

VII. Coulter Electronics, Ltd. St. Albans, Herts/England

VIII. General Diagnostic Division, Warner-Chilcott Laboratories Division, Morris Plains, N. J./USA 

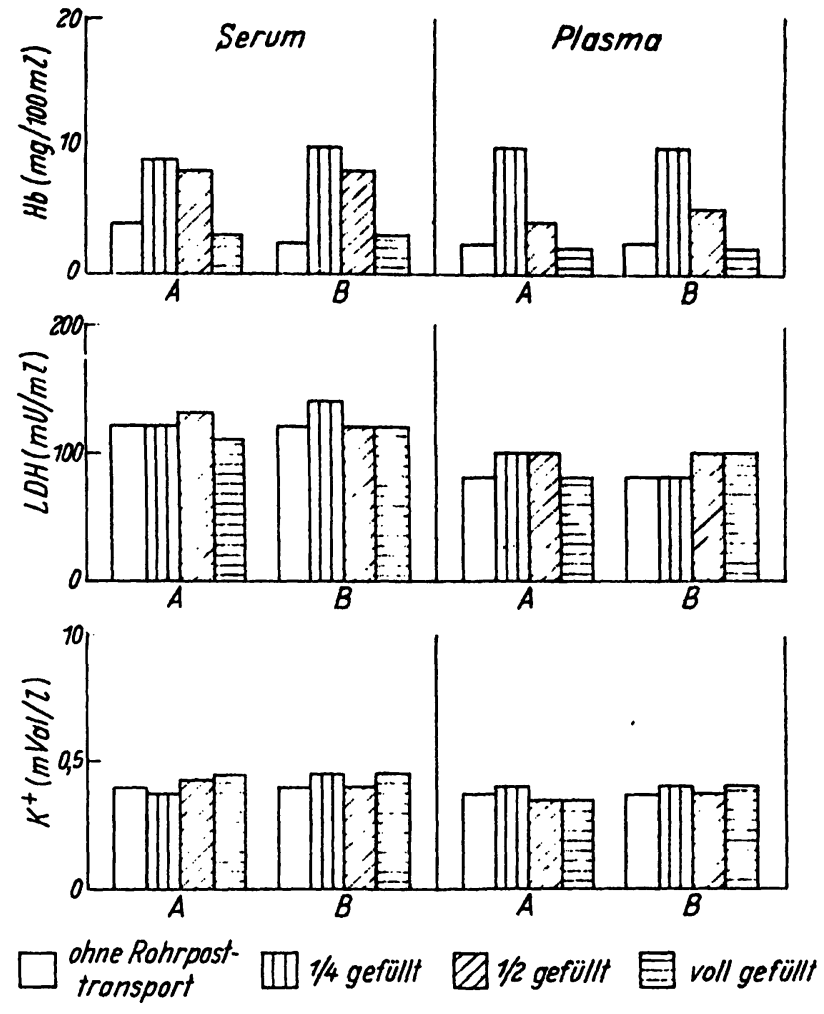

Abb. 2

Einfluß des Füllungsgrades der Probenröhrchen auf die Hämolyse: A: $3 \mathrm{~m} / \mathrm{Sek}$. Geschwindigkeit, keine Weichen $(n=3)$ B: $8 \mathrm{~m} /$ Sek. Geschwindigkeit, 10 Weichen $(n=3)$, Fahrstrecke $600 \mathrm{~m}$
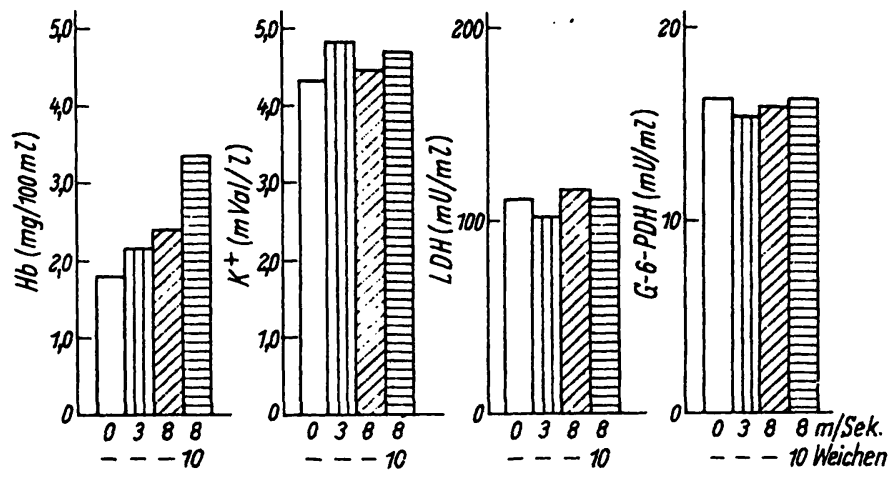

Abb. 3

Einfluß von Weichen und Fahrgeschwindigkeit auf Vollblut während des Rohrposttransportes: Serumspiegel von Hämoglobin, Kalium, Lactat-Dehydrogenase und Glucose-6-phosphat-Dehydrogenase vor und nach Rohrposttransport. Proberöhrchen bis zum Stopfen gefüllt $(n=6)$

keit von $8 \mathrm{~m} /$ Sek. bei gleichzeitigem Passieren von 10 Weichen. Im Gegensatz zur Hämoglobinkonzentration im Serum blieben LDH und Kalium-Werte auch bei Versand unvollständig gefüllter Proberöhrchen unbeeinflußt vom Rohrpostversuch.

Zunehmende Fahrgeschwindigkeit und Stoßeffekte durch Passieren von Weichen verursachen nur eine geringe Zunahme der Hämolyse bei randvoll gefüllten Proberöhrchen (Abb. 3). Zwar steigen die Hämoglobinwerte im Serum etwas an, bleiben jedoch sämtlich im Normalbereich, der von $0-5 \mathrm{mg} / 100 \mathrm{~m} l$ angegeben wird (1). Wie zu erwarten, finden sich keine Anstiege der Kaliumkonzentration oder der LDH- bzw. G-6-PDH-Aktivitäten. Bei einer Fahrgeschwindigkeit von $2 \mathrm{~m} / \mathrm{Sek}$. wurde keine mit der Länge der durchfahrenen Strecke zunehmende Hämoglobinkonzentration im Serum für einen Streckenbereich von $0-1,2 \mathrm{~km}$ beobachtet, während bei einer Geschwindigkeit von $8 \mathrm{~m} / \mathrm{Sek}$. die Hämoglobinkonzentration. im Serum bei $60 \mathrm{~m}$ Streckenlänge um $65 \%$, bei $600 \mathrm{~m}$ Streckenlänge um $100 \%$ und bei $1,2 \mathrm{~km}$ Streckenlänge um $300 \%$ zunahmen $(n=6)$.

Unter Standardbedingungen - Fahrgeschwindigkeit $3 \mathrm{~m} /$ Sek., $600 \mathrm{~m}$ Fahrstrecke, kein Passieren von Weichen - wurde in Serienversuchen das Ausmaß der
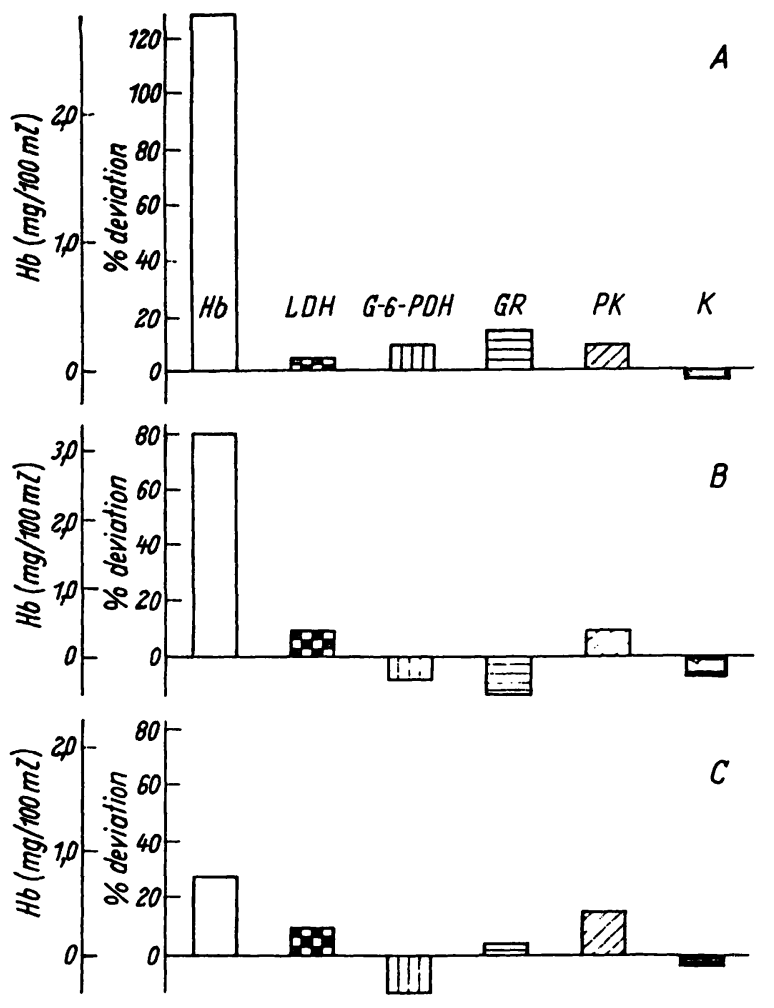

Abb. 4

Rohrposttransport von pathologisch veränderten Blutproben $(A, n=29)$, Normalblutproben verschiedener Personen ( $B, \mathrm{Hb}$ $\mathrm{n}=61) \mathrm{LDH} \mathrm{n}=21, \mathrm{GR} \mathrm{n}=26, \mathrm{PK} \mathrm{n}=36$, Kalium $\mathrm{n}=49$ ) und Blutproben eines Spenders, die in 18 verschiedenen Läufen die Rohrpost durchlaufen haben (C)

Serumspiegel von erythrocyteneigenen Substanzen dargestellt als prozentuale Abweichung von den nicht transportierten Vergleichswerten. Hämoglobinwerte zusätzlich absolut in $\mathrm{mg} / 100 \mathrm{ml}$ dargestellt

Hämolyse in Proben einer Gruppe gesunder Personen, $(n=61)$, in einer Gruppe krankhaft veränderter Seren ${ }^{1}$, $(n=29)$ und an Proben eines Blutspenders $(n=18)$, miteinander verglichen (Abb. 4).

Die Ergebnisse sind als prozentuale Abweichungen von den Kontrollwerten, die an nicht transportierten Proben ermittelt wurden, angegeben, um einen gemeinsamen Bezugspunkt zu erhalten. Die absolute Konzentration des Hämoglobins macht den Grad des Hämoglobinaustrittes aus den Erythrocyten deutlich. Alle Hämoglobinwerte im Serum lagen im Bereich von 0-3 mg/100 ml. Die Abweichungen von LDH, G-6-PDH, GR, PK und

1) Magencarcinom, Bronchopneumonie, Adipositas, Cholecystitis, primär-chronische Polyarthritis, Niereninsuffizienz, Polycythämie, Tumoranämie, extrem exhöhte Blutsenkungsgeschwindigkeit, myeloișche Leukämie, Gelbsucht bei Gallenblasenerkrankung, Gelbsucht bei Hepatitis, Asthma bronchiale, perniciöse Anämie, Herzinfarkt. 
Kalium bewegten sich im Bereich der Schwankungsbreite der Methoden. Die Hämoglobinkonzentration im Serum war sowohl in den Proben von Normalpersonen wie in den Proben krankhaft veränderten. Blutes höher als in den Parallelversuchen mit Spenderblut. Diese Unterschiede sind darauf zurückzuführen, daß bei den Versuchen am Spenderblut im Gegensatz zu den beiden anderen Gruppen alle Röhrchen gleichmäßig bis zum Rand gefüllt werden konnten. Obwohl aufgrund des unterschiedlichen Füllungsgrades der transportierten Blutproben keine optimalen Transportbedingungen vorlagen, war die durchschnittliche Konzentration des Hämoglobins im Serum der beiden Untersuchüngsgruppen nur halb so groß wie diejenige, die wir in einer unausgelesenen Gruppe von Blutproben fanden, die auf herkömmliche Weise ins Laboratorium transportiert wurden (Tab. 1).

Tab. 1

Mittlere Serumhämoglobinkonzentration in normalen und pathologisch veränderten Blutproben vor und nach Rohrposttransport im Vergleich zu einer unausgewählten Gruppe von Serumproben aus dem täglichen Laboratoriumseingang (Hol- und Bringedienst)

\begin{tabular}{|c|c|c|c|}
\hline & & $\begin{array}{l}\text { Hämoglobin } \\
\text { in } \mathrm{mg} / 100 \mathrm{ml}\end{array}$ & $\begin{array}{c}\text { Anzahl der } \\
\text { Proben }\end{array}$ \\
\hline \multicolumn{2}{|c|}{$\begin{array}{l}\text { Unausgewählte Serumproben aus } \\
\text { dem täglichen Laboreingang kein } \\
\text { Rohrposttransport }\end{array}$} & 7,85 & 44 \\
\hline $\begin{array}{l}\text { Normalblut- } \\
\text { proben }\end{array}$ & $\left\{\begin{array}{l}\text { ohne Transport } \\
\text { mit Transport }\end{array}\right.$ & $\begin{array}{l}2,2 \\
3,0\end{array}$ & $\begin{array}{l}26 \\
86\end{array}$ \\
\hline \multirow{2}{*}{$\begin{array}{l}\text { Pathologisch } \\
\text { veränderte } \\
\text { Blutproben }\end{array}$} & $\int$ ohne Transport & 2,7 & 22 \\
\hline & I nach Transport & 3,0 & 29 \\
\hline
\end{tabular}

Die klinisch-chemische Untersuchung der transportierten normalen wie pathologisch veränderten Blutproben ergab keine Abweichungen der Meßwerte in den eingangs angeführten Analyseverfahren von denjenigen, die an den nicht transportierten Vergleichsproben ermittelt wurden (Tab. 2). Auch bei der Ermittlung hämatologisch-serologischer Laboratoriumsdaten fanden sich keine signifikanten Abweichungen in den Ergebnissen (Tab. 3). Es wurden jeweils 10 bzw. 20 Parallelversuche für jeden der oben angeführten Teste durchgeführt.

Der Transport von Blutkonserven führt, wie zu erwarten, zu einer wesentlich stärkeren Schädigung der Erythrocyten mit Austritt von erythrocyteneigenen Komponenten in das Serum als es bei Nativ- oder Citratblut der Fall ist (Abb. 5). Hämoglobin, LDH und Kalium zeigen einen deutlichen Anstieg ihrer Konzentrationen im Überstehenden der Konserven in Abhängigkeit von der Fahrgeschwindigkeit, Streckenlänge und Anzahl der
Tab. 2

Einfluß von Rohrposttransport auf die Ergebnisse klinisch-chemischer Fahrgeschwindigkeit $3 \mathrm{~m} / \mathrm{Sek}$., $600 \mathrm{~m}$ Streckenlänge, keine Weichen

\begin{tabular}{|c|c|c|c|}
\hline $\begin{array}{l}\text { Art der } \\
\text { Bestimmung }\end{array}$ & $\begin{array}{c}\text { Meßergebnis } \\
\text { ohne } \\
\text { Rohrposttransport }\end{array}$ & $\begin{array}{c}\text { Meßergebnis } \\
\text { mit } \\
\text { Rohrposttransport }\end{array}$ & $\begin{array}{l}\text { Anzahl der } \\
\text { transp. } \\
\text { Proben }\end{array}$ \\
\hline Enzyme & $\mathrm{mU} / \mathrm{ml}$ & $\mathrm{mU} / \mathrm{ml}$ & \\
\hline $\begin{array}{l}\text { GOT } \\
\text { GPT } \\
\text { GLDH } \\
\text { alk. P'ase } \\
\text { saure P'ase } \\
\text { LDH } \\
\text { CPK }\end{array}$ & $\begin{array}{r}8,6 \\
13,5 \\
0,9 \\
33 \\
9,3 \\
105 \\
3,7\end{array}$ & 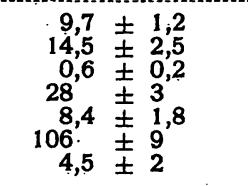 & $\begin{array}{r}10 \\
9 \\
9 \\
10 \\
10 \\
21 \\
8\end{array}$ \\
\hline Elektrolyte & $\mathrm{mVal} / \mathrm{l}$ & $\mathrm{m} \mathrm{Val} / \mathrm{l}$ & \\
\hline $\begin{array}{l}\mathrm{Na} \\
\mathrm{K} \\
\mathrm{Ca} \\
\mathrm{Cl} \\
\mathrm{PO}\end{array}$ & $\begin{array}{c}140 \\
3,5 \\
4,75 \\
100 \\
3,0\end{array}$ & $\begin{aligned} 141 & \pm 1 \\
3,4 & \pm 0 \\
4,7 & \pm 0,1 \\
107 & \pm 38 \\
2,9 & \pm 0,5\end{aligned}$ & $\begin{array}{l}19 \\
19 \\
10 \\
18 \\
10\end{array}$ \\
\hline Substrate & $\mathrm{mg} / 100 \mathrm{ml}$ & $\mathrm{mg} / 100 \mathrm{ml}$ & \\
\hline $\begin{array}{l}\text { Bilirubin } \\
\text { Harnstoff } \\
\text { Harnsäure } \\
\text { Kreatinin } \\
\text { Cholesterin } \\
\text { Fe }\end{array}$ & $\begin{array}{c}0,45 \\
45,2 \\
4,5 \\
1,03 \\
279^{-1} \cdot 10^{-3} \\
91\end{array}$ & $\begin{array}{c}0,39 \pm 0,2 \\
46,7 \pm 5,4 \\
4,7 \pm 0,03 \\
1,02 \pm 0 \\
269 \pm 12 \\
104 \pm 8 \cdot 10^{-3}\end{array}$ & $\begin{array}{r}10 \\
9 \\
10 \\
10 \\
10 \\
18\end{array}$ \\
\hline $\begin{array}{l}\text { Ges. Eiwei } \beta \\
\text { g/100 m! } \\
\text { Elektrophorese }\end{array}$ & 5,9 & $5,7 \pm 0,14$ & 10 \\
\hline $\begin{array}{ll}\text { Alb. } & \text { rel. } \% \\
\text { Glob. } \alpha_{2} & \text { rel. } \% \\
\text { Gilob. } \alpha_{3} & \text { rel. } \% \\
\text { Glob. } \beta & \text { rel. } \% \\
\text { Glob. } \gamma & \text { rel. } \%\end{array}$ & $\begin{array}{r}55 \\
5 \\
4 \\
12 \\
24\end{array}$ & $\begin{array}{l}58 \\
4,4 \\
2,6 \\
11 \\
24\end{array}$ & $\begin{array}{l}10 \\
10 \\
10 \\
10 \\
10\end{array}$ \\
\hline
\end{tabular}

passierten Weichen. Gewaschene Erythrocytensuspensionen weisen - wie theoretisch zu erwarten - wesentlich stärkere Anstiege dieser Meßgrößen auf.

\section{Diskussion}

Die Entnahme von Untersuchungsgut vom Patienten, die vorübergehende Aufbewahrung und der Transport zum Arbeitsplatz im Labor müssen als ein Teil der Analyse betrachtet werden. Ihre Handhabung muß mit der gleichen Sorgfalt vorgenommen werden, wie die Analyse im Laboratorium selbst, um eine optimale Zuverlässigkeit der Laboratoriumsdiagnostik zu erzielen. Trotz aller Bemühungen kann ein völlig störungsfreier Transport nicht erreicht werden. Jede Art von Transportsystem wird in Abhängigkeit von seinem technischen Aufbau Vor- und Nachteile für den Transport von Laboratoriumsmaterial aufweisen.

Bei der Benutzung der Rohrpost muß vor allen Dingen die Zerstörung der zellulären Anteile des Blutes und hier vor allen Dingen diejenige der quantitativ weit überwiegenden Erythrocyten als Störfaktor für die klinischchemische Analyse in Betracht gezogen werden. Der

Tab. 3

Meßergebnisse hämatologisch-serologischer Bestimmungen ohne und mit Rohrposttransport

\begin{tabular}{|c|c|c|c|c|}
\hline & ohne Rohrposttransport & mit Rohrposttransport & mit Rohrposttransport & $\mathbf{n}$ \\
\hline $\begin{array}{l}\text { Geschwindigkeit } \\
\text { Prothrombin-Zeit (\%) } \\
\text { Thrombin-Zeit (\%) } \\
\text { Recalcifizierungs-Zeit (Sek.) } \\
\text { Faktor V (Sek.) } \\
\text { Blutgruppen } \\
\text { Antistreptolysintiter (E) } \\
\text { Rheumafaktor (WAALER-RosE) } \\
\text { Erythrocyten (Coulter-Counter) } \\
\text { Leucocyten (Coulter-Counter) } \\
\text { Thrombocyten in Heparinblut }\end{array}$ & $\begin{array}{l}\overline{100} \\
13,2 \\
86 \\
36,4 \\
\overline{40} \\
1: 32 \\
4,5 \cdot 10^{\circ} \\
6 \cdot 10^{3} \\
206 \cdot 10^{3}\end{array}$ & $\begin{array}{c}3 \mathrm{~m} / \mathrm{sec} . \\
100 \\
13,0 \pm 0,6 \\
111 \pm 21 \\
36,5 \pm 3,2 \\
\text { unverằndert } \\
40 \\
1: 32 \\
4,34 \pm 0,1 \cdot 10^{\circ} \\
6,2 \pm 0,4 \cdot 10^{3} \\
238 \pm 39 \cdot 10^{3}\end{array}$ & $\begin{array}{l}1008 \mathrm{~m} / \mathrm{sec} . \\
14,6 \pm 1 \\
90 \pm 11 \\
39 \pm 2 \\
\text { unverä̀ndert } \\
40 \\
1: 32 \\
= \\
=\end{array}$ & $\begin{array}{l}10 \\
10 \\
10 \\
10 \\
10 \\
10 \\
10 \\
\left.20^{*}\right) \\
\left.20^{* *}\right) \\
8^{*}\end{array}$ \\
\hline
\end{tabular}

*) 20 Blutproben berechnet auf $4,5 \cdot 10^{\circ}$ als Ausgangswert

**) 20 Blutproben berechnet auf 6000 als Ausgangswert 


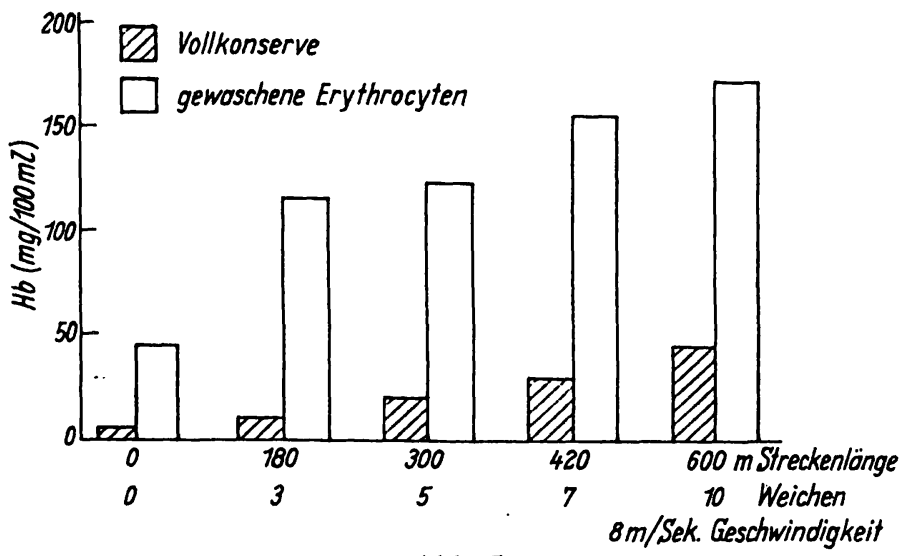

Abb. 5

Hämoglobinkonzentration im Überstehenden von Vollblutkonserven, die während des Rohrposttransportes ansteigenden mechanischen Belastungen ausgesetzt wurden. Transportgeschwindigkeit $8 \mathrm{~m} /$ Sek. $(n=2)$

Eintritt erythrocyteneigener Substanzen in das Serum wird nur dann ins Gewicht fallen, wenn ein hoher Konzentrationsgradient zwischen Serum und Erythrocyt vorhanden ist. Wie aus Tabelle 4 hervorgeht, gilt dieses

Tabe. 4

Konzentrationsgradienten zwischen Erythrocyt und Plasma für erythrocyteneigene Komponenten nach CARA WAY (13).

Errechnete Abweichungen von Meßergebnissen bei Hämolyseraten entsprechend $100 \mathrm{mg} / 100 \mathrm{ml} \mathrm{Hb}$ Plasma-Konzentration $\frac{\text { entsprechend } 10 \text { und } 100 \mathrm{mg} / 100 \mathrm{ml} \mathrm{Hb} \text { Plasma-Konzentration }}{\text { Errechnete Abweichung der }}$ Meßergebnisse im Plasma

Komponente $\begin{array}{cc}\text { Konz. im Erythrocyt entsprechend einer Hb-Konzen- } \\ \text { Konz. im Plasma }\end{array} \begin{gathered}\text { tration von: } \\ 10 \mathrm{mg} / 100 \mathrm{ml} \quad 100 \mathrm{mg} / 100 \mathrm{ml}\end{gathered}$

\begin{tabular}{lcrr}
\hline Hb & $10^{4}$ & & \\
Arginase & $10^{s}$ & $30,0 \%$ & $300,0 \%$ \\
LDH & 160 & $4,8 \%$ & $48,0 \%$ \\
Saure Phosphatase & 67 & $2,0 \%$ & $20,0 \%$ \\
Kalium & 22,7 & $0,7 \%$ & $7,0 \%$ \\
GPT & 6,7 & $0,2 \%$ & $2,0 \%$ \\
GOT & 40 & $1,2 \%$ & $12,0 \%$ \\
\hline
\end{tabular}

aber vorwiegend nur für das Hämoglobin, die Arginase und mit Einschränkung für die LDH. Obwohl man nicht annehmen kann, daß sich für alle Substanzen gleiche Austrittsraten als Folge einer Wandschädigung der Erythrocyten finden, zeigen die Ergebnisse, daß tatsächlich das Hämoglobin und die LDH mit den höchsten Konzentrationsgradienten zuerst vermehrt im Serum gefunden werden und damit die empfindlichsten Parameter für eine Hämolyse darstellen. Ein meßbarer Anstieg der Kaliumkonzentration im Serum transportierter Blutproben konnte bei uns in allen gemachten Versuchen überhaupt nicht beobachtet werden. Lediglich in Blutkonserven, bei denen schon primär eine sehr hohe Kaliumkonzentration im Serum als Folge lagerungsibedingter Erythrocytenschädigung vorlag, fanden wir hohe Kaliumwerte im Überstehenden. Der Austritt von Hämoglobin in das Serum kann zu einer Verfälschung der Analyse führen, wenn photometrisch bei einer Wellenlänge zwischen 400 und $500 \mathrm{~nm}$ gearbeitet wird. Bei unverdünnten Seren würde ein solcher Irrtum beobachtet werden, wenn die Hämoglobinkonzentration im Serum $1 \mathrm{mg} / 100 \mathrm{ml}$ überschreitet. $\mathrm{Da}$ aber im allgemeinen mit einer mindestens $10 \mathrm{mal}$ höheren Verdünnung des Serums zu rechnen ist, kann man bis zu einer Konzentration von $10^{\prime} \mathrm{mg} / 100 \mathrm{ml}$ Hämoglobin im Serum keine wesentlichen Störungen der Analyse erwarten und falls solche auftreten, sie durch Mitführen von Blindwerten ausschalten. Unter den von uns gewählten Betriebsbedingungen von $3 \mathrm{~m} / \mathrm{Sek}$. Fahrgeschwindigkeit und $600 \mathrm{~m}$ weichenfreier Fahrstrecke war die entstehende Hämolyse im Hinblick auf die Meßergebnisse im Laboratorium belanglos. Der Vergleich der Hämoglobinwerte (Tab. 1) von Seren, die dem Rohrposttransport unterworfen waren, mit denjenigen, die an Serumproben gewonnen wurden, die mit dem Hol- und Bringedienst ins Labor transportiert wurden, zeigt, daß die Transportbedingungen einer Rohrpost bessere Resultate ermöglichen als ein Transport von Blutproben auf herkömmliche Weise. Auch unter extremen Bedingungen wie zum Beispiel Verlängerung der Fahrstrecke, Einschalten von Weichen, erhöhter Fahrgeschwindigkeit oder schlechter Füllung der Gefäße werden keine Hämoglobinkonzentrationen im Serum gemessen, welche zu einer sichtbaren Hämolyse führen. Diese ist erst bei Hämoglobinwerten über $20 \mathrm{mg} / 100 \mathrm{ml}$ zu beobachten (14). Unter den Faktoren, die die Größe der Hämolyserate bestimmen, ist der Grad der Gefäßfüllung als entscheidend anzusehen. Schon bei niedrigen Fahrgeschwindigkeiten und beim Ausschalten von Weichen kommt es bei geringer Gefäßfüllung zu einer drei- bis vierfach höheren Hämolyserate als bei randvoll gefüllten Transportgefäßen. Dieser Effekt wird bei höheren Fahrgeschwindigkeiten und Einschalten von Weichen weiter verstärkt. Trotzdem haben wir Hämoglobinkonzentrationen über $10 \mathrm{mg} / 100 \mathrm{~m} l$ nur in seltenen Fällen, über $20 \mathrm{mg} / 100 \mathrm{ml}$ überhaupt nicht gesehen. Wenn die oben angeführten Überlegungen hinsichtlich der Relation zwischen den Konzentrationen erythrocyteneigener. Komponenten im Serum und dem ausgetretenen Hämoglobin zu Recht bestehen, dann müßte man in unseren Versuchsreihen keine oder nur geringfügige Veränderungen in den ermittelten Analysenergebnissen von Proben, die mit der Rohrpost transportiert waren, im Vergleich zu denen, die nicht transportiert waren, finden. In der Tat konnten bei keinem der geprüften Systeme (s. o.). Abweichungen von den Vergleichswerten, die den Bereich der angewandten Methoden überschreiten, festgestellt werden.

Besondere Kritik wird der Bestimmung des Eisens im Serum im Hinblick auf eine Verfälschung der Ergebnisse durch Hämolyse in der Blutprobe entgegengebracht. Kritisch wirkt sich eine Mikrohämolyse jedoch nur dann aus, wenn mit einer Eisenbestimmungsmethode gearbeitet wird, die das Hämeisen miterfaßt oder durch Gegenwart von Hämeisen gestört wird. Bei Anwendung der Eisenbestimmung nach TrINDER (15) mit Bathophenanthrolin-di-sulfonat ist dies nicht der Fall und eine Störung der Reaktion ist bis zur Serumkonzentration von $120 \mu \mathrm{g} / 100 \mathrm{~m} l$ Hämeisen entsprechend einer Hämoglobinkonzentration von $30 \mathrm{mg} / 100 \mathrm{ml}$ nicht $\mathrm{zu}$ erwarten.

Die Ergebnisse von Untersuchungen von Serumeiweißkörpern, von denen besonders die Aktivitätsbestimmungen von Serumenzymen, immunologische Untersuchungsverfahren sowie die Analyse von Gerinnungs- 
faktoren von Bedeutung sind, zeigen, daß ein Rohrposttransport von Blutproben nicht zu Alterationen dieser Eiweißkörper, welche die Analyse stören würden, führen. Gerade für die Analyse dieser Komponenten dürfte die Schnelligkeit, mit der der Transport erfolgt, ein wesentlicher Vorteil des Rohrposttransportes gegenüber der herkömmlichen Anlieferung darstellen, da die Denaturierungstate dieser Eiweißkomponenten mit zunehmender Zeit in mehr oder weniger starkem Ausmaße ansteigt. Auch im hämatologischen Laboratorium finden Untersuchungsautomaten, welche mit ungerinnbarem Blut bzw. verdünnten Blutzellsuspensionen arbeiten, mehr und mehr Eingang. Diese Blutproben lassen sich leicht mit der Rohrpost zum Meßplatz im Labor überführen. Aus diesem Grunde wurden in unsere Versuchsreihen auch der Transport von Blutzellsuspensionen in physiologischer Kochsalzlösung für die Zählung am Coulter-Counter und von Heparinblut zur Thrombocytenzählung eingeschlossen. Auch für diese Untersuchungsverfahren kann ohne Beeinträchtigung der Analysenergebnisse die Rohrpost zum Transport des Untersuchungsgutes herangezogen werden.

Beim Versand von Blutkonserven muß mit einer stärkeren Hämolyse gerechnet werden, welche im wesentlichen durch die Vorschädigung der Erythrocyten infolge der Konservierung und Lagerung hervorgerufen sein dürfte. Die bei unseren Versuchen beobachteten Hämoglobinkonzentrationen im Überstehenden der Vollblutkonserven überschritten jedoch nicht einen Wert von $50 \mathrm{mg} /$ $100 \mathrm{ml}$. Dieser Wert schließt auch das haptoglobingebundene Hämoglobin ein, da bei der von uns verwandten Bestimmungsmethode das haptoglobingebundene Eisen mit erfaßt wurde. Bei einer normalen Haptoglobinkonzentration im Empfängerblutserum wie in der Blutkonserve werden diese Hämoglobinmengen an Haptoglobin gebunden und damit für den Empfängerorganismus unschädlich. Hingewiesen werden soll noch auf den recht hohen Kaliumspiegel, den wir schon primär im Überstehenden der Ganzblutkonserven fanden. Er überschritt in einzelnen Fällen $8 \mathrm{mVal} / l$ und wurde durch den Rohrposttransport nur noch geringfügig gesteigert. Das beobachtete Ausmaß von Hämolyse in Blutkonserven bei Rohrposttransport kann mit aller Wahrscheinlichkeit noch wesentlich verringert werden, wenn es gelingen würde, die Blutkonserven- behälter randvoll zu füllen und damit den Schütteleffekt weitgehend zu eliminieren. Aufgrund der dargelegten Ergebnisse scheint es gerechtfertigt, den Transport von Konserven über ein Rohrpostsystem vorzunehmen. Die Ergebnisse der Versuche mit Fahrgeschwindigkeiten bis zu $8 \mathrm{~m} / \mathrm{Sek}$. lassen auch den Transport in einem allgemeinen Rohrpostsystem mit höheren Geschwindigkeiten möglich erscheinen. Allerdings dürfte der Rohrpostversand von gewaschenen Erythrocytensuspensionen nicht möglich sein.

Unsere Versuchsserie hat gezeigt, daß unter kontrollierten Betriebsbedingungen der Versand von Untersuchungsmaterial von den Stationen in das Laboratorium und von Blutkonserven innerhalb der Kliniken möglich ist. Ein solches Transportsystem läßt sich am besten in einer speziellen für den Transport für Laborgut bestimmten Leitung durchführen, die mit geringerer Fahrgeschwindigkeit unter Vermeidung von Weichen und Druckkammern betrieben werden kann. Da eine gleichmäßige Füllung der Gefäße zum Transport von Vollblut nicht immer erreicht werden kann, ist eine Reduzierung der auf das Untersuchungsgut während des Transportes einwirkenden mechanischen und kinetischen Kräfte wesentlich für einen störungsfreien Transportablauf. Die Empfangsstation sollte ein Abrollen ankommender Rohrpostbüchsen ermöglichen, um ein plötzliches $\mathrm{Ab}$ stoppen der Rohrpostbehälter zu vermeiden. Die direkte Leitung von den Stationen zum Labor erlaubt außerdem einen unverzögerten Transport der Rohrpostbüchsen zu Zeiten maximaler Belastungen des allgemeinen Rohrpostsystems und erleichtert wesentlich eine infolge von Behälterbruch etwa notẉendige Reinigung oder Desinfektion der Fahrleitungen. Für den Transport von Laborgut empfiehlt sich eine $124 \mathrm{~mm}$ Rohrpostanlage, deren Behälterkapazität von 40 Probenröhrchen oder 27 Probenbüchsen den Arbeitsaufwand für Beladung und Entnahme in einem vertretbaren Rahmen hält, und damit den Rationalisierungseffekt der Rohrpost für die Arbeit auf Station und im Laboratorium voll zur Geltung kommen läßt.

Die Autoren sind Herrn Priv.-Dozent Dr. H. Dercher und Herrn Priv.-Dozent Dr. H. Polrwoda für die Ausführung immunologischer und hämatologisch-serologischer Untersuchungen außerordentlich zu Dank verpflichtet. Den Herren P. HrLGER, R. PAPST, P. J. ROCKeL und U. SChröter gilt unser Dank für sorgfältige technische Mitarbeit.

\section{Literatur}

1. McClellan, E. K., R. Nakamura, W. HaAs, D. L. Moyer und G. M. Kunitake, Amer. J. Clin. Path. 42, 152 (1964). - 2. Wu, H., J. Biochem. (Tokyo) 2, 189 (1923). - 3. CROSBY, W. H. und F. W. Furth, Blood, 11, 380 (1956). - 4. Delbrück, A., Klin. Wschr. 40, 677 (1962). - 5. Rick, W. und T. V. Hausamen, Z. analyt. Chem. 212, 267 (1965). - 6. Richterich, R., Klinische Chemie, Theorie und Praxis. Akademische Verlagsanstalt Frankfurt/Main, (1965). - 7. Jendrassik, L. und P. Groof, Biochem. Z. 287, 81 (1938). - 8. Folin, O., Hoppe-Seyler's Z. physiol. Chem. 228, 268 (1934). - 9. Weichselbaum, T. E., Amer. J. Clin. Path. Techn.
Section, 10, 40 (1946). - 10. Skeggs, L. T. und H. Hochstrasser, Ann. N. Y. Acad. Sc. 102, 144 (1962). - 11. KöHLER, W., Die Serologie des Rheumatismus und der Streptokokkeninfektionen. Beiträge zur Hygiene u. Epidemiologie, Heft 9, 3rd Edition Leipzig (1963). - 12. Svartz, N. und K. Schlossmann, Acta med. Scand. 142, 420 (1952). - 13. Caraway, W. T., Amer. J. Clin. Path. 37, 44 (1962). - 14. Behrendt, H., Chemistry of erythrocytes, Thomas, Springfield, Ill. USA (1957). - 15. TRINDER, P., J. Clin. Path. London 9, 170 (1956).

Doz. Dr. A. Delbrück Krankenhaus Oststadt 3 Hannover, Podbielskistr. 380 